\title{
Shadow pitching deviates ball release position: kinematic analysis in high school baseball pitchers
}

Shigeaki Miyazaki ${ }^{1}$, Go Yamako ${ }^{2 *}$, Koji Totoribe ${ }^{1}$, Tomohisa Sekimoto ${ }^{3}$, Yuko Kadowaki ${ }^{4}$, Kurumi Tsuruta ${ }^{5}$ and Etsuo Chosa ${ }^{1,3}$

\begin{abstract}
Background: Although shadow pitching, commonly called "towel drill," is recommended to improve the throwing motion for the rehabilitation of pitching disorders before the initiation of a throwing program aimed at returning to throwing using a ball, the motion differs from that of normal throwing. Learning improper motion during ball release (BR) may increase shoulder joint forces. Abnormal throwing biomechanics leads to injures. However, there has been no study of shadow pitching focusing on the BR position. The purpose of the present study was to evaluate the BR position and kinematic differences between shadow pitching and normal throwing. In addition, the effect of setting a target guide for BR position on throwing motion was examined in shadow pitching.

Methods: The participants included in this study were 20 healthy male students who were overhand right-handed pitchers with no pain induced by a throwing motion. Participants performed normal throwing (task 1), shadow pitching using a hand towel (task 2), and shadow pitching by setting a target of the BR position (task 3). A motion capture system was used to evaluate kinematic differences in throwing motions, respectively. Examination items comprised joint angles and the differences in BR position.

Results: BR position of task 2 shifted significantly toward the anterior, leftward, and downward directions compared with task 1. The distance of BR position between tasks 1 and 2 was $24 \pm 10 \%$. However, task 3 had decreased BR deviation compared with task 2 (the distance between 3 and 1 was $14 \pm 7 \%$ ). Kinematic differences were observed among groups at BR. For shoulder joint, task 2 showed the highest value in abduction and horizontal adduction among groups. In spine flexion, left rotation and thorax flexion, task 2 was significantly higher than task 1. Task 3 showed small differences compared with task 1.

Conclusions: The BR position of shadow pitching deviated significantly in the anterior, leftward, and downward directions compared with normal throwing. Furthermore, we demonstrated that the setting of BR target reduces this deviation. Thus, the target of BR position should be set accurately during shadow pitching exercises in the process of rehabilitation.
\end{abstract}

Keywords: Shadow pitching, Throwing motion, Kinematic differences, Ball release target, Pitching disorders

\footnotetext{
* Correspondence: g.yamako@cc.miyazaki-u.ac.jp

${ }^{2}$ Department of Mechanical Design Systems Engineering, Faculty of

Engineering, University of Miyazaki, 1-1 Gakuen Kibanadai-nishi, Miyazaki,

Miyazaki 889-2192, Japan

Full list of author information is available at the end of the article
}

C C The Author(s). 2021 Open Access This article is licensed under a Creative Commons Attribution 4.0 International License, which permits use, sharing, adaptation, distribution and reproduction in any medium or format, as long as you give appropriate credit to the original author(s) and the source, provide a link to the Creative Commons licence, and indicate if changes were made. The images or other third party material in this article are included in the article's Creative Commons licence, unless indicated otherwise in a credit line to the material. If material is not included in the article's Creative Commons licence and your intended use is not permitted by statutory regulation or exceeds the permitted use, you will need to obtain permission directly from the copyright holder. To view a copy of this licence, visit http://creativecommons.org/licenses/by/4.0/ The Creative Commons Public Domain Dedication waiver (http://creativecommons.org/publicdomain/zero/1.0/) applies to the data made available in this article, unless otherwise stated in a credit line to the data. 


\section{Background}

The throwing motion in baseball is a full-body exercise. It requires a kinetic chain among each joint of the lower limbs, the trunk, and the upper limbs. Kinetic energy is transmitted into a ball through the chain [1-4]. Pitching disorders caused by abnormal throwing biomechanics can be induced by the dysfunction of even a single joint. In addition, Chalmers et al. [5]. reported that altered knee flexion at ball release, early trunk rotation, loss of shoulder rotational range of motion, and increased elbow flexion at ball release may increase shoulder and elbow torques and risk for injury. Therefore, abnormal throwing biomechanics leads to injuries in the shoulder and elbow joints [6, 7].

Biomechanical studies on throwing motion have evaluated joint angles, forces, and torques using an optical motion capture system and have indicated correlations to injuries [6, 8-12]. Excessive shoulder horizontal abduction [13] increases the anterior joint force during maximum shoulder external rotation (MER) [11], resulting in internal impingement, rotator cuff tears, and superior labral anterior to posterior lesions [14]. Maximum shoulder joint force is reached around the time of ball release (BR) [15, 16]. Fleisig et al. [15] reported that $1090 \mathrm{~N}$ of shoulder compressive force was produced after BR. The risk of glenoid labrum injury may increase with level of competition, labrum injury may also occur from the combination of humeral translation, compression, and internal rotation [15]. These studies indicate the importance of establishing a proper throwing motion to prevent injuries and encourage the investigation of throwing kinematics during rehabilitation and training.

Shadow pitching, commonly called "towel drill," is recommended to improve the throwing motion for the rehabilitation of pitching disorders before the initiation of a throwing program aimed at returning to throwing using a ball $[17,18]$. Shadow pitching is also performed as a warm-up exercise before throwing of the ball. The pitchers practice the throwing motion by holding a hand towel with their fingers. However, in daily clinical practice, there seems to be a difference in the motion between shadow pitching and normal throwing using a ball. Specifically, the BR position of shadow pitching may deviate to the anterior directions compared with normal throwing because there is no BR target. A previous biomechanical study showed that the glenohumeral external rotation angle was significantly lower in shadow pitching than in normal throwing at MER [19]. However, there has been no study of shadow pitching focusing on the $\mathrm{BR}$ position. Changes in BR position may induce greater shoulder joint forces [12].

The purpose of the present study was to evaluate the BR position and kinematic differences between shadow pitching and normal throwing using an optical motion capture system. In addition, the effect of setting a target guide for BR position on throwing motion was examined in shadow pitching. We hypothesized that the BR position of shadow pitching deviates to the anterior directions compared to normal throwing using a ball. We also hypothesized that the target of BR position reduces the kinematic differences between normal and shadow pitching.

\section{Methods \\ Design}

This study used a controlled laboratory design with counterbalanced conditions in a laboratory setting. Primary independent variable was task (normal throwing, shadow pitching using a hand towel, and shadow pitching by setting a target of the BR position). Primary outcomes included various joints angles and the BR position.

\section{Participants}

The participants included in this study were 20 healthy male students (age, $16.5 \pm 0.8$ years (mean \pm standard deviation [SD]); height, $1.72 \pm 0.05 \mathrm{~m}$; weight, $64.8 \pm 7.2 \mathrm{~kg}$ ) who were right-handed pitchers with no pain induced by a throwing motion. No participants were injured or recovering from an injury at the time of testing, and none had previous shoulder or elbow surgery. This study was conducted after receiving the approval of the Research Ethics Committee of the Faculty of Medicine, University of Miyazaki. This study was conducted in accordance with the Declaration of Helsinki. Because the subjects were minors, we explained the purpose and the content of the study orally and in written form to the subjects and their parents, and obtained written informed consent.

\section{Procedures}

The participants performed three tasks of throwing motions in the following order. Task 1 performed normal throwing using a ball (approximately $146 \mathrm{~g}$ ), task 2 performed shadow pitching using a hand towel $(66 \mathrm{~g}, 30 \mathrm{~cm}$ in length), and task 3 performed shadow pitching using a hand towel with a BR position setting. In task 3, a target of BR position was set by placing an artificial leather sheet ( $40 \mathrm{~cm}$ in length, $10 \mathrm{~cm}$ in width) (Fig. 1A). Fastball was the method of gripping wherein the first to fourth fingers were placed on the seam of the ball and the first finger was placed at the center of the ball. The towel was rounded to hold. As far as possible, the grip on the towel was similar to that on the ball.

Throwing motions were measured using an optical motion capture system (Vicon Nexus, Vicon Motion Systems, London, UK) with 10 infrared cameras (MX 3 and MXT 20, Vicon Motion Systems). The subjects were 
A

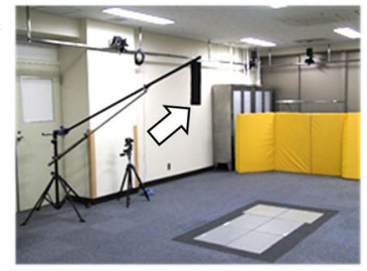

a

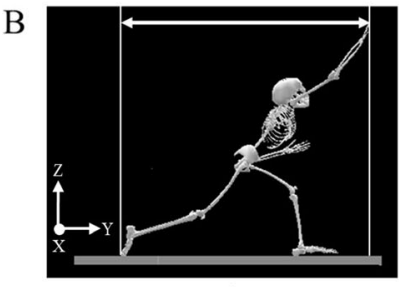

a

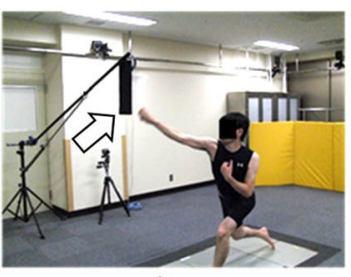

b

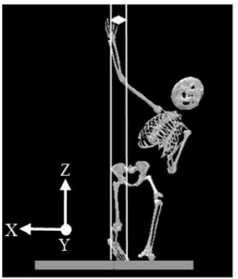

b

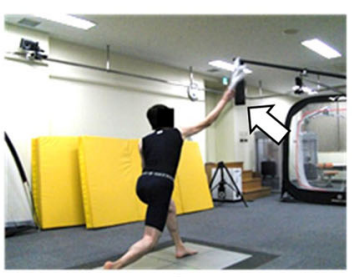

c

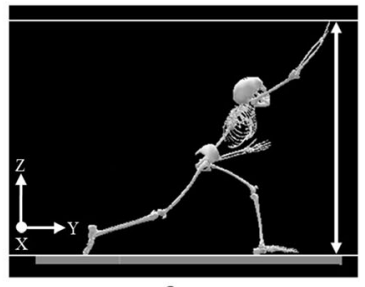

C

Fig. 1 (a) Setting a target of ball release (BR) position (arrows). The BR target was placed with reference to the BR position of normal throwing using a ball. a: Setting the target of BR position, b: Left-side view of shadow pitching, c: Posterior view of shadow pitching. (b) Definition of BR position. BR position was defined as a distance to the right finger from the right toe at BR position. a: Direction of anterior/posterior, b: Transverse (left/right) direction, c: Vertical (upward/downward) direction

no clothes on their upper body but wore skin-tight clothes (Under Armour, Maryland, USA) on their lower body. Thirty-five reflective markers (14-mm diameter) were attached to the participants according to the Plugin-Gait model protocol [20, 21]. The sampling frequency of the system was set at $250 \mathrm{~Hz}$. Two video cameras (Bonita Video Camera Bonita 720c, Vicon Motion Systems) were also used with a sampling frequency of Procedures $125 \mathrm{~Hz}$, synchronized with the motion capture system. A global coordinate system was established, denoting the landmarks of a baseball field. The Y-axis is oriented from the mound toward the catcher and the Xaxis from the first base toward the third base, which is orthogonal to the Y-axis. Further, the Z-axis is vertically oriented upward (Fig. 1B).

The measurement of throwing motions was performed indoor using a practice net (2ZM595, Mizuno, Osaka, Japan) placed six meters in front of the support leg at wind up. The subjects warmed up and practiced so that they would pitch naturally. Before testing, the subjects completed a preparation routine, including stretching, and warm-up throwing. They were asked to pitch the ball as fast as possible. Instructions to quantify the throwing motion included 1) throwing in a pitching motion, 2) no wind up throwing (a throwing technique in which the pitcher throws the ball by stopping at the thoracic level or hip), 3) fastball as the pitch type, and 4) a 20-s interval between pitches. Each throwing task was performed five times in each participant.

\section{Data processing}

Using the plug-in gait model, kinematic data were obtained from positions of each reflective marker [20, 21]. The throwing kinematics were evaluated at MER and $B R$, and $B R$ time was determined using a video camera. The BR time for shadow pitching was defined as the time when the extension of the elbow reached the maximum value. The elbow extension was the highest during the BR phase while throwing the ball [22]. Kinematic examination items comprised the joint angles of the shoulder (horizontal adduction/horizontal abduction, abduction/adduction, and internal rotation/external rotation), elbow (flexion/extension), hip (flexion/extension, adduction/abduction, and internal rotation/external rotation), knee (flexion/extension), ankle (dorsiflexion/plantar flexion), spine (flexion/extension, lateral bending, and rotation), thorax (flexion/extension, left/right lateral bending, and left/ right rotation), and pelvis (anterior/posterior tilt, left/right turn, and left/right rotation).

The differences in BR position among the tasks were assessed. The BR position was BR position was defined as the distance from the second metatarsal head of the right foot to the second metacarpal head of the right hand in anterior/posterior, transverse (left/right), and vertical (upward/downward) directions (Fig. 1B) based on the global coordinate system. BR position was normalized by the subject's body height. The stride length of throwing was not significantly different among the tasks.

The throwing type of participants was evaluated using the arm slot angle based on the study by Escamilla et al. [23]. The angle was divided into three throwing groups: overhand $\left(\leq 40^{\circ}\right.$ arm slot angle), three-quarter $\left(41^{\circ}\right.$ to $69^{\circ}$ arm slot angle), and sidearm ( $\geq 70^{\circ}$ arm slot angle).

\section{Statistical analysis}

A statistical power analysis was performed using EZR software version 1.38 (Saitama Medical Center, Jichi 
Medical University, Saitama, Japan) [24]. We conducted a sample size calculation based on the power of the corresponding t-test with a primary endpoint of the right shoulder horizontal adduction angle, which greatly affects the deviation of the BR position. The SD of the right shoulder horizontal adduction angle at BR position in tasks 1 and 2 was nine degrees, and the value for task 2 was expected to be at least seven degrees greater than that of task 1 . We conducted a sample size calculation $(\alpha=0.05$, power $=0.8)$ based on $\mathrm{SD}=9$ and $\Delta=7$ (difference in the means for both tasks) as estimated. The results indicated that the required sample size was 16 . To allow for some withdrawals, we set the required number of subjects at 20 .

In order to analyze the motion of the best performance, data from the motion, which the subjects were most satisfied with, were used as representative values. All data were presented as mean $\pm \mathrm{SD}$. Analysis software, IBM SPSS Version 21 (IBM Corp., Armonk, NY, USA) was used. After confirming the data followed a normal distribution, we performed one- factor repeated measures analysis of variance (ANOVA). For the items in which a significant difference was observed, Bonferroni correction of the corresponding t-test was applied for comparison. The significance level was set at 0.05 .

\section{Results}

Seventeen participants were classified as the threequarter (mean angle of the arm slot angle: $59.3 \pm 7.7^{\circ}$ ) and three were sidearm $\left(75.5 \pm 4.7^{\circ}\right)$.

Significant differences were noted in BR position among tasks (Table 1). The BR position of task 2 significantly deviated toward the anterior, leftward, and downward directions compared with task 1 . The distance of BR position between tasks 1 and 2 was $24 \pm 10 \%$. However, task 3 had decreased BR deviation compared with task 2 (the distance between 3 and 1 was $14 \pm 7 \%$ ).

Significant differences were observed among tasks in various joints angles at BR (Table 2). In the shoulder joint of the throwing side, task 2 showed the highest value in abduction and horizontal adduction and the lowest value in external rotation. In spine flexion, left rotation, and thorax flexion, task 2 was significantly higher than task 1. Task 3 showed small differences compared with tasks 1 (Table 2 and Fig. 2).

Significant differences were observed among tasks in various joint angles at MER (Table 3). In the shoulder joint of the throwing side, task 2 showed the highest horizontal adduction and lowest external rotation. Evaluation of horizontal adduction showed no significant difference between tasks 1 and 3. Thorax and spine flexion and spine left rotation were significantly higher in task 2 than in task 1 (Table 3 and Fig. 2), and spine flexion and thorax flexion of task 3 were significantly lower than those of task 2.

\section{Discussion}

During rehabilitation, pitchers need to stabilize their physical status and obtain proper throwing motion to return to pitching. This study evaluated motion differences between shadow pitching and normal throwing. Compared to normal throwing, the BR position deviates in shadow pitching, resulting in different kinematics at BR and MER between shadow pitching and normal throwing. This improper throwing of leaning the upper body forward increased spine rotation and shoulder horizontal adduction during the acceleration phase. However, the kinematics of shadow pitching with the target setting of BR position was similar to that of normal throwing.

In this study, the shoulder horizontal adduction angle of normal throwing at BR was within the range of values in reported in previous studies [15, 25-28]. Fleisig et al. [26] reported that 33 high school pitchers showed $10^{\circ}$ shoulder horizontal adduction at BR. Avoiding excessive shoulder angles should be emphasized. Tanaka et al. [12] reported that the minimum anterior-posterior and vertical shear forces on the shoulder joint were at $10.7^{\circ}$ for shoulder horizontal adduction and $80.6^{\circ}$ for shoulder abduction at BR. A $5^{\circ}$ deviation from these shoulder angles indicates significantly increased joint forces. Our study demonstrated that shadow pitching showed excessive horizontal adduction and abduction compared with

Table 1 The difference in the BR position among tasks

\begin{tabular}{|c|c|c|c|c|c|}
\hline \multirow[b]{3}{*}{ Direction of BR position } & \multicolumn{5}{|c|}{ Arm Acceleration } \\
\hline & \multicolumn{5}{|l|}{$\overline{B R}$} \\
\hline & Task 1 & Task 2 & Task 3 & One factor repeated measures ANOVA & $\begin{array}{l}\text { Bonferroni correction } \\
p \text {-value }\end{array}$ \\
\hline Anterior (+) or Posterior (-) & $78 \pm 8$ & $91 \pm 6^{a}$ & $86 \pm 9^{b c}$ & $\mathrm{~F}=66.206, p<.001$ & $<.001^{a c}, .001^{b}$ \\
\hline Transverse: Right (+) or Left $(-)$ & $14 \pm 11$ & $4 \pm 8^{a}$ & $7 \pm 8^{b c}$ & $\mathrm{~F}=25.836, p<.001$ & $<.001^{\mathrm{a}}, .015^{\mathrm{b}}, .001^{\mathrm{c}}$ \\
\hline Vertical: Upward (+) or Downward (-) & $76 \pm 7$ & $59 \pm 10^{a}$ & $70 \pm 8^{b c}$ & $\mathrm{~F}=42.588, p<.001$ & $<.001^{\mathrm{ab}}, .001^{\mathrm{c}}$ \\
\hline
\end{tabular}

All values are in percentages. Values are presented as mean \pm standard deviation

Abbreviation: BR Ball release, ANOVA Analysis of variance

a Significant difference between task 1 and task 2

b Significant difference between task 2 and task 3

c Significant difference between task 1 and task 3 
Table 2 Joint angles at BR position

\begin{tabular}{|c|c|c|c|c|c|}
\hline \multirow[b]{3}{*}{ Direction of Motion } & \multicolumn{5}{|c|}{ Arm Acceleration } \\
\hline & \multicolumn{5}{|l|}{$\mathrm{BR}$} \\
\hline & Task 1 & Task 2 & Task 3 & $\begin{array}{l}\text { One-factor repeated measures } \\
\text { ANOVA }\end{array}$ & $\begin{array}{l}\text { Bonferroni } \\
\text { correction } \\
p \text {-value }\end{array}$ \\
\hline \multicolumn{6}{|l|}{ Right Shoulder } \\
\hline $\begin{array}{l}\text { Horizontal Adduction (+) or Abduction } \\
(-)\end{array}$ & $2.3 \pm 7.9$ & $17.3 \pm 9.2^{a}$ & $7.8 \pm 7.9^{b c}$ & $\mathrm{~F}=36.902, p<.001$ & $<.001^{\mathrm{a} b}, .001^{\mathrm{c}}$ \\
\hline Abduction (+) or Adduction (-) & $98.1 \pm 7.2$ & $103.2 \pm 6.2^{\mathrm{a}}$ & $100.1 \pm 9.1$ & $\mathrm{~F}=5.036, p=.023$ & $<.001^{\mathrm{a}}$ \\
\hline $\begin{array}{l}\text { Internal Rotation }(+) \text { or External Rotation } \\
(-)\end{array}$ & $\begin{array}{l}-91.8 \pm \\
16.3\end{array}$ & $-78.8 \pm 21.4$ & $-85.3 \pm 15.7$ & $\mathrm{~F}=11.496, p<.001$ & $.002^{\mathrm{a}}, .041^{\mathrm{c}}$ \\
\hline \multicolumn{6}{|l|}{ Spine } \\
\hline Flexion $(+)$ or Extension (-) & $11.4 \pm 7.4$ & $23.3 \pm 7.9^{a}$ & $18.9 \pm 8.0^{c}$ & $\mathrm{~F}=26.104, p<.001$ & $<.001^{a}, .002^{c}$ \\
\hline Lateral Bending: Left $(+)$ or Right $(-)$ & $32.7 \pm 9.8$ & $28.7 \pm 9.0^{a}$ & $30.0 \pm 7.7$ & $\mathrm{~F}=6.078, p=.005$ & $.007^{\mathrm{a}}$ \\
\hline Rotation: Left (+) or Right (-) & $17.7 \pm 7.3$ & $23.2 \pm 6.9^{a}$ & $21.1 \pm 8.1$ & $F=7.437, p=.002$ & $.007^{\mathrm{a}}$ \\
\hline \multicolumn{6}{|l|}{ Thorax } \\
\hline Flexion (+) or Extension (-) & $32.3 \pm 9.8$ & $42.0 \pm 8.6^{a}$ & $37.7 \pm 9.1 \mathrm{bc}$ & $\mathrm{F}=21.538, p<.001$ & $<.001^{a}, .030^{b}, .002^{c}$ \\
\hline
\end{tabular}

All angles are in degrees. Values are presented as mean \pm standard deviation Abbreviation: $B R$ Ball release, ANOVA Analysis of variance

a Significant difference between task 1 and task 2

${ }^{\text {b }}$ Significant difference between task 2 and task 3

c Significant difference between task 1 and task 3

normal throwing $\left(15^{\circ}\right.$ difference in horizontal adduction, $5^{\circ}$ difference in abduction). However, the target of BR position $\left(5.5^{\circ}\right.$ deviation in horizontal adduction, $2^{\circ}$ deviation in abduction, compared with normal throwing) decreases excessive shoulder motions. Therefore, the target of BR position is required in shadow pitching during rehabilitation.

The MER angle of shadow pitching was significantly lower than that of normal throwing. This finding is consistent with a previous study by Okamoto et al. [19]. The shoulder external rotation during the throwing motion is explained as a lagging back phenomenon in which the movement of the forearm and hand segment lag behind the upper segment when switching from arm cocking to arm acceleration $[3,10]$. There may be reduced MER angle with shadow pitching because of the reduced moment due to the lack of the ball mass. In addition, this mass helps keep the upright posture of the upper body during the acceleration phase. The extension in the thorax and spine at MER was significantly lower in

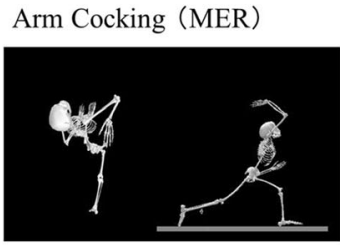

Top view

Right-side view

Arm Acceleration (BR)

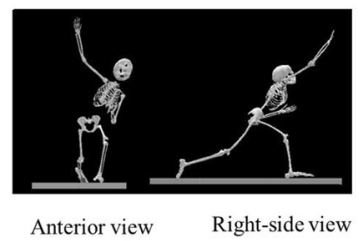

Task 1

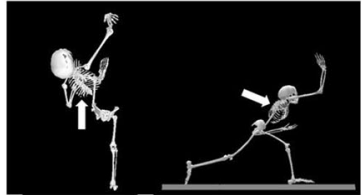

Top view Right-side view

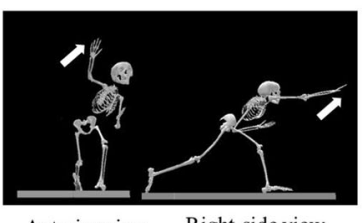

Task 2

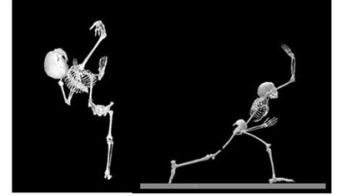

Top view Right-side view

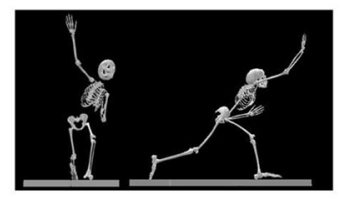

Anterior view Right-side view

Task 3

Fig. 2 The arm cocking (MER) and arm acceleration (BR) positions for each task. At the MER, the throwing motion of task 2 was not accurately performed in the spinal column and thoracic extension position compared with tasks 1 and 3 (arrows). At the BR position, the leaning of upper limbs of task 2 was greater than those of tasks 1 and 3. Abbreviation: MER maximum shoulder external rotation, BR ball release 
Table 3 Joint angles at MER

\begin{tabular}{|c|c|c|c|c|c|}
\hline \multirow[b]{3}{*}{ Direction of Motion } & \multicolumn{5}{|c|}{ Arm Cocking } \\
\hline & \multicolumn{5}{|l|}{ MER } \\
\hline & Task 1 & Task 2 & Task 3 & $\begin{array}{l}\text { One-factor repeated measures } \\
\text { ANOVA }\end{array}$ & $\begin{array}{l}\text { Bonferroni } \\
\text { correction } \\
p \text {-value }\end{array}$ \\
\hline \multicolumn{6}{|l|}{ Right Shoulder } \\
\hline $\begin{array}{l}\text { Horizontal Adduction (+) or Abduction } \\
(-)\end{array}$ & $3.5 \pm 6.0$ & $12.6 \pm 9.0^{a}$ & $5.0 \pm 7.9^{b}$ & $\mathrm{~F}=14.768, p<.001$ & $.001^{\mathrm{ab}}$ \\
\hline $\begin{array}{l}\text { Internal Rotation }(+) \text { or External } \\
\text { Rotation }(-)\end{array}$ & $\begin{array}{l}-160.0 \pm \\
13.9\end{array}$ & $-149.7 \pm 14.3$ & $\begin{array}{l}-153.7 \pm 12.6 \\
\mathrm{bc}\end{array}$ & $\mathrm{F}=24.664, p<.001$ & 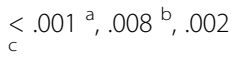 \\
\hline \multicolumn{6}{|l|}{ Spine } \\
\hline Flexion (+) or Extension (-) & $-6.6 \pm 8.2$ & $6.4 \pm 10.2^{a}$ & $0.0 \pm 10.3^{b c}$ & $\mathrm{~F}=24.748, p<.001$ & ${ }_{c} .001^{a}, .003^{b}, .011$ \\
\hline Rotation: Left (+) or Right (-) & $6.3 \pm 9.2$ & $12.0 \pm 8.0^{a}$ & $9.3 \pm 8.7$ & $\mathrm{~F}=8.436, p=.001$ & $.005^{\mathrm{a}}$ \\
\hline \multicolumn{6}{|l|}{ Thorax } \\
\hline Flexion (+) or Extension (-) & $21.0 \pm 8.4$ & $30.8 \pm 9.9^{a}$ & $25.7 \pm 9.0^{b c}$ & $\mathrm{~F}=24.572, p<.001$ & ${ }_{c}^{<.001^{a}, .002^{b}, .006}$ \\
\hline
\end{tabular}

All angles are in degree. Values are presented as mean \pm standard deviation Abbreviation: MER Maximum shoulder external rotation, ANOVA Analysis of variance

a Significant difference between task 1 and task 2

${ }^{\mathrm{b}}$ Significant difference between task 2 and task 3

c Significant difference between task 1 and task 3

shadow pitching than in normal throwing. This indicates that shadow pitching was not able to stretch their chest during the acceleration phase, which may increase the shoulder joint loads. Not only glenohumeral external rotation but also scapular posterior tilt and thoracic extension contribute to the shoulder external rotation during the throwing motion [10]. These restrictions of movement have a greater effect on loads acting on the glenohumeral joint and can lead to pitching disorders.

From our results on shadow pitching biomechanics, the following points are crucial to create an effective rehabilitation program for pitching disorders: (1) recognizing the gap of kinematics between shadow pitching and normal throwing using a ball; (2) ensuring sufficient flexibility of the spine and the thorax; (3) setting a target of BR position during shadow pitching exercises; (4) transitioning to throwing using a ball after learning the appropriate BR position in shadow pitching exercise. Being aware of these points will reduce the differences between shadow pitching and normal throwing using and can facilitate safer and more effective rehabilitation.

The study has some limitations. First, data collection was done in a laboratory setting. Our laboratory did not have a regulation mound and there was not enough space for the throwing distance. Moreover, the subjects performed throwing without shoes. Therefore, throwing performance may have been affected by these conditions $[29,30]$. Second, the age of the participants is about 16.5 years old. Their throwing motion is not mature, which may cause variability of the kinematics [31]. Third, skin movement artifact for positions of reflective markers did not completely disappear [32, 33]. This may cause errors in calculating kinematic parameters. Fourth, a sampling rate of $250 \mathrm{~Hz}$ may not have been enough to calculate kinetic parameters around MER and BR. Our further studies will focus on kinetics of shadow pitching.

\section{Conclusions}

In summary, our kinematic analysis demonstrated that the BR position of shadow pitching deviated significantly to the anterior, leftward, and downward directions compared with normal throwing. Furthermore, we showed that the setting of target of BR position can reduce this deviation. Thus, the target of BR position should be set accurately during shadow pitching exercises in the process of rehabilitation.

\section{Abbreviations}

ANOVA: Analysis of variance; BR: Ball release; MER: Maximum shoulder external rotation; SD: Standard deviation

\section{Acknowledgements}

We thank Masaru Ochiai and Niroshan G Punchihewa for their important efforts in identifying and recruiting participants.

\section{Authors' contributions}

Research conception and design: SM, GY. Data collection: SM, GY, Koji Totoribe. Interpretation of data: SM, GY, Koji Totoribe, TS. Statistical analysis: SM, YK, Kurumi Tsuruta. Drafting the manuscript: SM. Manuscript review: GY, Koji Totoribe, TS, EC. Study supervision: EC. All authors had full access to data in the study and made substantial contributions in preparing the final version of the paper. All authors approved the final manuscript, and agreed to be accountable for all aspects of this research.

\section{Funding}

This study was partially supported by the Special Education and Research Funding (collaborative project) by the Ministry of Education, Culture, Sport, 
Science and Technology (MEXT) for the elucidation of the mechanism of sports injuries and disorders -construction of sports medical support system- (from fiscal 2007 to fiscal 2011). This work was also supported by JSPS KAKENHI Grant Numbers JP17K01362. The funder had no role in the design of the study, the collection, analysis, and interpretations of data, or in writing the manuscript.

\section{Availability of data and materials}

The datasets used and/or analyzed during the current study are available from the corresponding author on reasonable request.

\section{Declarations}

\section{Ethics approval and consent to participate}

This study was conducted after receiving the approval of the Research Ethics Committee of the Faculty of Medicine, University of Miyazaki (Approval number 2015-052). This study was conducted in accordance with the Declaration of Helsinki. Because the subjects were minors, we explained the purpose and the content of the study orally and in written form to the subjects and their parents, and obtained written informed consent. Their rights were protected.

\section{Consent for publication}

Not applicable.

\section{Competing interests}

The authors declare that they have no competing interests.

\section{Author details}

${ }^{1}$ Rehabilitation Unit, University of Miyazaki Hospital, 5200 Kihara Kiyotake, Miyazaki, Miyazaki 889-1692, Japan. ${ }^{2}$ Department of Mechanical Design Systems Engineering, Faculty of Engineering, University of Miyazaki, 1-1 Gakuen Kibanadai-nishi, Miyazaki, Miyazaki 889-2192, Japan. ${ }^{3}$ Department of Orthopaedic Surgery, Faculty of Medicine, University of Miyazaki, 5200 Kihara Kiyotake, Miyazaki, Miyazaki 889-1692, Japan. ${ }^{4}$ Clinical Research Support Center, University of Miyazaki Hospital, 5200 Kihara Kiyotake, Miyazaki, Miyazaki 889-1692, Japan. ${ }^{5}$ School of Nursing, Faculty of Medicine, University of Miyazaki, 5200 Kihara Kiyotake, Miyazaki, Miyazaki 889-1692, Japan.

\section{Received: 15 December 2020 Accepted: 5 March 2021} Published online: 17 March 2021

\section{References}

1. Feltner M, Dapena J. Dynamics of the shoulder and elbow joints of the throwing arm during a baseball pitch. J Appl Biomech. 1986;2(4):235-59.

2. Kibler WB. The role of the scapula in athletic shoulder function. Am J Sports Med. 1998;26(2):325-37. https://doi.org/10.1177/03635465980260022801.

3. Kreighbaum E, Berthels KM. Biomechanics A qualitative approach for studying human movement. In: Throwlike and pushlike movement patterns. 4th ed. Boston: Allyn and Bacon; 1996. p. 335-54.

4. Van der Hoeven $H$, Kibler WB. Shoulder injuries in tennis players. Br J Sports Med. 2006;40(5):435-40. https://doi.org/10.1136/bjsm.2005.023218.

5. Chalmers PN, Wimmer MA, Verma NN, Cole BJ, Romeo AA, Cvetanovich GL, Pearl ML. The relationship between pitching mechanics and injury: a review of current concepts. Sports Health. 2017;9(3):216-21. https://doi.org/10.11 77/1941738116686545.

6. Davis JT, Limpisvasti O, Fluhme D, Mohr KJ, Yocum LA, Elattrache NS, Jobe FW. The effect of pitching biomechanics on the upper extremity in youth and adolescent baseball pitchers. Am J Sports Med. 2009;37(8):1484-91. https://doi.org/10.1177/0363546509340226.

7. Oyama S, Yu B, Blackburn JT, Padua DA, Li L, Myers JB. Effect of excessive contralateral trunk tilt on pitching biomechanics and performance in high school baseball pitchers. Am J Sports Med. 2013;41(10):2430-8. https://doi. org/10.1177/0363546513496547.

8. Aguinaldo AL, Chambers H. Correlation of throwing mechanics with elbow valgus load in adult baseball pitchers. Am J Sports Med. 2009;37(10):2043-8. https://doi.org/10.1177/0363546509336721.

9. Laughlin WA, Fleisig GS, Scillia AJ, Aune KT, Cain EL Jr, Dugas JR. Deficiencies in pitching biomechanics in baseball players with a history of superior labrum anterior-posterior repair. Am J Sports Med. 2014;42(12): 2837-41. https://doi.org/10.1177/0363546514552183.
10. Miyashita K, Kobayashi H, Koshida S, Urabe Y. Glenohumeral, scapular, and thoracic angles at maximum shoulder external rotation in throwing. Am J Sports Med. 2010;38(2):363-8. https://doi.org/10.1177/0363546509347542.

11. Takagi Y, Oi T, Tanaka H, Inui H, Fujioka H, Tanaka J, Yoshiya S, Nobuhara K. Increased horizontal shoulder abduction is associated with an increase in shoulder joint load in baseball pitching. J Shoulder Elb Surg. 2014;23(12): 1757-62. https://doi.org/10.1016/j.jse.2014.03.005.

12. Tanaka H, Hayashi T, Inui H, Muto T, Ninomiya H, Nakamura Y, Yoshiya S, Nobuhara K. Estimation of shoulder behavior from the viewpoint of minimized shoulder joint load among adolescent baseball pitchers. Am J Sports Med. 2018;46(12):3007-13. https://doi.org/10.1177/0363546518789626.

13. Davidson PA, Elattrache NS, Jobe CM, Jobe FW. Rotator cuff and posteriorsuperior glenoid labrum injury associated with increased glenohumeral motion: a new site of impingement. J Shoulder Elb Surg. 1995;4(5):384-90. https://doi.org/10.1016/S1058-2746(95)80023-9.

14. Mihata T, McGarry MH, Kinoshita M, Lee TQ. Excessive glenohumeral horizontal abduction as occurs during the late cocking phase of the throwing motion can be critical for internal impingement. Am J Sports Med. 2010;38(2):369-74. https://doi.org/10.1177/0363546509346408.

15. Fleisig GS, Andrews JR, Dillman CJ, Escamilla RF. Kinetics of baseball pitching with implications about injury mechanisms. Am J Sports Med. 1995;23(2):233-9. https://doi.org/10.1177/036354659502300218.

16. Werner SL, Gill TJ, Murray TA, Cook TD, Hawkins RJ. Relationships between throwing mechanics and shoulder distraction in professional baseball pitchers. Am J Sports Med. 2001;29(3):354-8. https://doi.org/10.1177/036354 65010290031701.

17. Wilk KE, Meister K, Andrews JR. Current concepts in the rehabilitation of the overhead throwing athlete. Am J Sports Med. 2002;30(1):136-51. https://doi. org/10.1177/03635465020300011201.

18. Wilk KE, Obma P, Simpson CD, Cain EL, Dugas JR, Andrews JR. Shoulder injuries in the overhead athlete. J Orthop Sports Phys Ther. 2009;39(2):3854. https://doi.org/10.2519/jospt.2009.2929.

19. Okamoto S, Endo Y, Saito R, Nakazawa R, Sakamoto M. Three-dimensional kinematic analysis of glenohumeral, scapular, and thoracic angles at maximum shoulder external rotation associated with baseball shadow pitching: comparison with normal pitching. J Phys Ther Sci. 2018;30(7):93842. https://doi.org/10.1589/jpts.30.938.

20. Davis RB, Õunpuu S, Tyburski D, Gage JR. A gait analysis data collection and reduction technique. Hum Mov Sci. 1991;10(5):575-87. https://doi.org/10.101 6/0167-9457(91)90046-Z.

21. Kadaba MP, Ramakrishnan HK, Wootten ME. Measurement of lower extremity kinematics during level walking. J Orthop Res. 1990;8(3):383-92. https://doi.org/10.1002/jor.1100080310.

22. Werner SL, Fleisig GS, Dillman CJ, Andrews JR. Biomechanics of the elbow during baseball pitching. J Orthop Sports Phys Ther. 1993;17(6):274-8. https://doi.org/10.2519/jospt.1993.17.6.274.

23. Escamilla RF, Slowik JS, Diffendaffer AZ, Fleisig GS. Differences among overhand, 3-quarter, and sidearm pitching biomechanics in professional baseball players. J Appl Biomech. 2018;34(5):377-85. https://doi.org/10.1123/jab.2017-0211.

24. Kanda Y. Investigation of the freely available easy-to-use software 'EZR' for medical statistics. Bone Marrow Transplant. 2013;48(3):452-8. https://doi. org/10.1038/bmt.2012.244.

25. Dillman CJ, Fleisig GS, Andrews JR. Biomechanics of pitching with emphasis upon shoulder kinematics. J Orthop Sports Phys Ther. 1993;18(2):402-8. https://doi.org/10.2519/jospt.1993.18.2.402.

26. Fleisig GS, Barrentine SW, Zheng N, Escamilla RF, Andrews JR. Kinematic and kinetic comparison of baseball pitching among various levels of development. J Biomech. 1999;32(12):1371-5. https://doi.org/10.1016/S00219290(99)00127-X.

27. Keeley DW, Hackett T, Keirns M, Sabick MB, Torry MR. A biomechanical analysis of youth pitching mechanics. J Pediatr Orthop. 2008;28(4):452-9. https://doi.org/10.1097/BPO.0b013e31816d7258.

28. Stodden DF, Fleisig GS, McLean SP, Andrews JR. Relationship of biomechanical factors to baseball pitching velocity: within pitcher variation. J Appl Biomech. 2005;21(1):44-56. https://doi.org/10.1123/jab.21.1.44.

29. Diffendaffer AZ, Slowik JS, Lo NJ, Drogosz M, Fleisig GS. The influence of mound height on baseball movement and pitching biomechanics. J Sci Med Sport. 2019;22(7):858-61. https://doi.org/10.1016/j.jsams.2019.01.012.

30. Fleisig GS, Diffendaffer AZ, Ivey B, Oi T. Do mound height and pitching distance affect youth baseball pitching biomechanics? Am J Sports Med. 2018;46(12):2996-3001. https://doi.org/10.1177/0363546518795890. 
31. Fleisig G, Chu Y, Weber A, Andrews J. Variability in baseball pitching biomechanics among various levels of competition. Sports Biomech. 2009, 8(1):10-21. https://doi.org/10.1080/14763140802629958.

32. Fukui T, Otake $\mathrm{Y}$, Kondo $\mathrm{T}$. In which direction does skin move during joint movement? Skin Res Technol. 2016;22(2):181-8. https://doi.org/10.1111/ srt.12248.

33. Zhang Y, Lloyd DG, Campbell AC, Alderson JA. Can the effect of soft tissue artefact be eliminated in upper-arm internal-external rotation? J Appl Biomech. 2011;27(3):258-65. https://doi.org/10.1123/jab.27.3.258.

\section{Publisher's Note}

Springer Nature remains neutral with regard to jurisdictional claims in published maps and institutional affiliations.

Ready to submit your research? Choose BMC and benefit from:

- fast, convenient online submission

- thorough peer review by experienced researchers in your field

- rapid publication on acceptance

- support for research data, including large and complex data types

- gold Open Access which fosters wider collaboration and increased citations

- maximum visibility for your research: over $100 \mathrm{M}$ website views per year

At BMC, research is always in progress.

Learn more biomedcentral.com/submissions 